\section{A SHORT HISTORY OF}

\section{TALMUDIC MEDICINE.}

By J. Snowman, M.D., M.R.C.P. John Bale, Sons \& Danielsson Ltd., London. 1935. Pp. 94. Price $3 / 6$ net.

Although Talmudic Medicine-i.e., the Medicine of the Jews between about 300 B.C. and 500 A.D. - has been dealt with in a number of books in different languages, Dr. Snowman's little book is the first of its kind in English, and thus, to some extent fills a gap in English medicohistorical literature.

This concise, but fairly comprehensive, booklet, opens with a chapter on The Environment of Talmudic Medicine in which the author points out the influence of Hippocrates and Galen on ancient Jewish medicine. The next chapter describes the Social Status of the Physician. Chapters III and IV deal with Anatomy, Physiology and Pathology. Chapters V to XIII are devoted to the Various Aspects of Medicine, Surgery and the Specialities, while the final chapter (XIV) concerns itself with Comparative and Experimental Medicine.

Although the information contained in this little book is interesting and, in all essential matters, very reliable, it is not altogether free from a few minor faults. Certain paragraphs which hardly come within the scope of Talmudic Medicinee.g., reference to a 12 th Century Jewish work on page 23 , or scriptural quotations regarding epilepsy on pages 39 and 40 might have been omitted, while some strikingly interesting and very pertinent facts, such as the ability of the Rabbis to differentiate between bloods of different animals, or their probable knowledge of the total amount of blood in the human body, might, with advantage have been included. Also, the more inquisitive reader would have welcomed a few more notes pointing out how much of the Rabbinical medical knowledge was original and how much was borrowed from the Greeks.

The book also contains a couple of errors of commission. Dr. Snowman's suggestion that the Rabbinical dictum : "the best of physicians is destined for Ghenna" applies to barbers rather than to physicians, not only is unwarranted but obviously does not help to elucidate the reason underlying this somewhat perplexing statement. The correct explanation is that even the best doctor cannot escape an occasional error of judgment leading to loss of human life.

We would also point out that it is incorrect to speak of Rabbi Samuel. That 3rd Century sage should be referred to either as Mar Samuel or simply as Samuel. Also, the statement that the Talmud contains the first reference to a vaginal speculum in medical history is erroneous ; Soranus of Ephesus used it about 100 years earlier.

These slight imperfections, however, do not in any way detract from the value of the book which we can earnestly recommend to all who are interested in medical history.

\section{AIDS $\sim$ TO OPHTHALMOLOGY.} (8th Edition).

By N. Bishop Harman, M.B., F.R.C.S. London : Baillière, Tindall \& Cox. Price $3 / 6.1935$.

This book has deservedly been one of the most popular of the "Aids" series, and the present edition brings it fully up-to-date. The most recent methods and views are brought into various parts of the book, and the layout of the subject matter has obviously been carefully reconsidered. Beyond the stock textbook information necessary for the student preparing for examinations, there are many pages of material most useful to the general practitioner, facing not only the clinical aspect of " eyes," but the economic and sociological sides. The presentation of the facts is clear and concise, and in the main the illustrations and diagrams are very good. The stress is laid on the commoner features of the subject, and the choice is well balanced, except perhaps for the tendency to present methods of treatment and forms of apparatus particularly liked by the author even though they be not those in common or accepted usage. This new edition makes a very efficient condensed guide to the simpler and broader issues of the subject of Ophthalmology. 